\title{
Plenilske pršice (Acari: Phytoseiidae), prvič najdene na gojenih rastlinah v Sloveniji v obdobju 2012-2017
}

\author{
Tanja BOHINC ${ }^{1}$, Serge KREITER ${ }^{2}$, Marie-Stephane TIXIER $^{2}$, Gijbertus VIERBERGEN $^{3}$, Stanislav TRDAN $^{*}$
}

Received June 28, 2018; accepted September 28, 2018.

Delo je prispelo 28. junija 2018, sprejeto 28. septembra 2018.

\section{IZVLEČEK}

V obdobju 2012-2017 smo na različnih gostiteljskih rastlinah v Sloveniji preučevali zastopanost domorodnih vrst plenilskih pršic. V obsežni raziskavi smo potrdili zastopanost vrst Amblyseius andersoni (Chant, 1957), Euseius finlandicus (Oudemans, 1915), Euseius gallicus (Kreiter \& Tixier, 2010), Euseius stipulatus (Athias-Henriot, 1960), Kampimodromus abberans (Oudemans, 1930), Neoseiulus californicus (McGregor, 1954), Paraseiulus triporus (Chant \& Shaul, 1982) in Phytoseius horridus (Ribaga, 1904). V prispevku predstavljamo vseh sedem vrst, za področje biotičnega varstva rastlin pa so najzanimivejše vrste $A$. andersoni, $N$. californicus in E. gallicus. Medtem ko sta prvi dve vrsti že vpisani na Seznam domorodnih vrst organizmov za namen biotičnega varstva rastlin, pa bo pršica E. gallicus na ta seznam uvrščena v bližnji prihodnosti. Vse tri vrste plenilskih pršic imajo velik aplikativni pomen in jih najdemo na velikem številu vrst gostiteljskih rastlin.

Ključne besede: plenilske pršice; Phytoseiidae; prve najdbe; biotično varstvo rastlin; Slovenija; Euseius gallicus

\section{ABSTRACT \\ PREDATORY MITES (ACARI: PHYTOSEIIDAE) FIRST RECORDED ON CULTIVATED PLANTS IN SLOVENIA IN THE PERIOD 2012-2017}

In the period 2012-2017 we investigated the occurrence of indigenous species of predatory mites in different cultivated plants in Slovenia. In a comprehensive study we confirmed the occurrence of the following predatory mites: Amblyseius andersoni (Chant, 1957), Euseius finlandicus (Oudemans, 1915), Euseius gallicus (Kreiter \& Tixier, 2010), Euseius stipulatus (Athias-Henriot, 1960), Kampimodromus abberans (Oudemans, 1930), Neoseiulus californicus (McGregor, 1954), Paraseiulus triporus (Chant \& Shaul, 1982) and Phytoseius horridus (Ribaga, 1904). In the paper all seven species are presented, but for the field of biological control $A$. andersoni, E. gallicus and N. californicus are the most interesting species. The first two of them are already on the List of indigenous organisms for the purpose of biological control, while the third will be placed into it in the near future. All three of them have a great potential in biological control, since they can be found in different host plants.

Key words: predatory mites; Phytoseiidae; first record; biological control; Slovenia; Euseius gallicus

\section{UVOD}

Plenilske pršice iz družine Phytoseiidae spadajo med pomembne biotične agense, ki lahko uspešno sodelujejo pri zatiranju človeškim očem težko vidnih škodljivih organizmov iz taksonov Tetranychoidea, Eriophyoidea, Thysanoptera in Homoptera (Stojnić et al., 2002) V sadovnjakih, vinogradih in na zelenjadnicah, gojenih na prostem in $\mathrm{v}$ zavarovanem prostoru (Palevsky et al., 1999), prehranjujejo pa se tudi $\mathrm{z}$ rastlinskim sokom in pelodom (Blackwood et al., 2001).

1 Univerza v Ljubljani, Biotehniška fakulteta, Odd. za agronomijo, Jamnikarjeva 101, SI-1000 Ljubljana, Slovenia, korespondenca: stanislav.trdan@bf.uni-lj.si

2 Montpellier SupAgro, UMR CBGP (SupAgro/Cirad/INRA/IRD), 755 Avenue du Campus Agropolus, CS 30016, 34988 Montferrier-sur-Lez cedex France

3 Ministry of Agriculture, Nature and Food Quality, NVWA, NPPO, NRC, Geertjesweg 15, 6706 EA, Wageningen, The Netherlands 
Tanja BOHINC in sod.

Namen našega prispevka je predstaviti rezultate vzorčenja domorodnih naravnih sovražnikov v obdobju 2012-2017, z namenom povečanja Seznama domorodnih vrst organizmov za namen biotičnega varstva rastlin v Sloveniji. V prispevku se osredotočamo na pomen pri nas prvič najdenih vrst plenilskih pršic $\mathrm{v}$ varstvu rastlin.

\section{MATERIALI IN METODE}

\subsection{Vzorčenje plenilskih pršic}

S spremljanjem zastopanosti plenilskih pršic smo začeli v letu 2012. Od junija do oktobra smo na različnih vrtninah in sadnih vrstah nabirali vzorce listov. Vzorčenje je junija potekalo na Zgornji Lipnici (46.322427; 14.187794) v travniškem sadovnjaku na navadni slivi. V avgustu smo $\mathrm{v}$ Slovenski Istri na različnih lokacijah nabirali vzorce vrtnin, v ekstenzivnem sadovnjaku na Laboratorijskem polju Biotehniške fakultete $(46.049403 ; 14.473137)$ pa smo vzorčili liste jablan, na katerih so bile predhodne vidne poškodbe rdeče sadne pršice (Panonychus ulmi [Koch]).

V letu 2014 smo od maja do oktobra v sklopu načrtnega vzorčenja škodljivih žuželk v dveh različnih travniških rastlinjakih na območju Ribnice in Kočevja nabirali liste jablan, kjer smo opazili poškodbe pršic prelk (Tetranychidae). Prvo vzorčenje je potekalo v $200 \mathrm{~m}^{2}$ velikem sadovnjaku v Rakitnici (45.69121, 14.756171), drugo pa v $150 \mathrm{~m}^{2}$ velikem sadovnjaku v Kočevski Reki $(45.571227 ; 14.809602)$.

V letu 2016 smo med aprilom in oktobrom v sklopu načrtovanega vzorčenja škodljivih žuželk na različnih lokacijah v Slovenski Istri nabirali vzorce gojenih in samoniklih rastlin. $\mathrm{V}$ septembru smo na večjem številu listov fige (Ficus carica L.) ugotovili poškodbe pršic prelk. Prvo vzorčenje je potekalo na figah v Vinjolah (45.501990; 13.620267), drugo pa na posestvu Purissima $(45.572714 ; 13.775552)$ v bližini Ankarana. Vzorčili smo fige, ki so rastle v bližini rastlinjakov.
S spremljanjem škodljivih žuželk smo nadaljevali v letu 2017. V jugozahodni Sloveniji smo na različnih lokacijah in gostiteljskih rastlinah nabrali poškodovane liste zaradi pršic prelk. 21. julija smo v Bukovici (45.89.5899; 13.665020) nabrali vzorce listov kumar in paprike, ki so jih gojili $\mathrm{v}$ rastlinjaku. $\mathrm{Na}$ isti dan smo $\mathrm{v}$ Šempetru pri Gorici $(45.93217 ; 13.64504)$ in v Novi Gorici (45.95657; 13.64259) nabrali liste malin oziroma vrtnic. V 21. avgusta smo $\mathrm{v}$ rastlinjaku na posestvu Purissima nabrali poškodovane liste paprik, na smokvi v Serminu (Bertokih) pa smo nabrali poškodovane liste smokve. 27. julija smo v Zgornji Pohanci (45.93848; 15.54116) na jagodah nabrali tiste liste, ki so kazali poškodbe zaradi fitofagnih pršic.

$\mathrm{V}$ vseh primerih smo nabrane liste shranili v plastične vrečke in jih v hladilni torbi odpeljali v Laboratorij za fitomedicino na Biotehniški fakulteti v Ljubljani, kjer smo pod stereomikropskopom vzorce pregledali. Najdene plenilske pršice smo shranili v $70 \%$ etanol.

\subsection{Determinacija plenilskih pršic}

Determinacija šestih vrst plenilskih pršic je bila izvedena na Montpellier SupAgro, UMR CBGP, SupAgro/CIRAD/INRA/IRD v Montpellieru v Franciji, vrste Euseius gallicus pa na National Reference Centre (NRC), National Plant Protection Organization (NPPO), Netherlands Food and Consumer Product Safety Authority (NVWA), Ministry of Agriculture, Nature and Food Quality v Wageningenu na Nizozemskem.

Morfološka determinacija vrst je bila izvedena na način, ki ga nazorno opisujejo Kreiter et al. (2018ab).

\section{REZULTATI IN DISKUSIJA}

\subsection{Vrste iz rodu Euseius}

\subsubsection{Euseius stipulatus (Athias-Henriot, 1960)}

Pršico Euseius stipulatus (Athias-Henriot) smo v Sloveniji prvič našli 27. julija 2017 v plastenjaku z jagodami (Fragaria x ananassa Duchesne) V vasi Zgornja Pohanca. Najdena vrsta plenilske pršice spada V rod Euseius, kamor je bilo doslej uvrščenih 212 vrst (McMurtry in sod., 2013). Rod Euseius spada v četrto skupino plenilskih pršic, kamor spadajo plenilske pršice, ki za svoj razvoj potrebujejo pelod. Poleg peloda pa se prehranjujejo tudi s fitofagnimi pršicami. Med sadnimi vrstami ji najbolj ustrezajo pelod mandljevca, slive, češnje in marelice (Bouras in Papadoulis, 2005). To pršico najdemo tudi na vinski trti (Global Biodiversity Information Facility, 2018).

Zastopanost plenilskih pršic iz rodu Euseius v nasadih citrusov je na območju Sredozemlja zelo velika (AbadMoyano in sod., 2010). Vrsta E. stipulatus je značilni predstavnik južnega območja zahodnega Palearktika (Gbif, 2018). Pojavlja se v Grčiji, Turčiji, Italiji, Španiji 
in Alžiriji (Bouras and Papadoulis, 2005), pa tudi v Turčiji, Franciji, Tuniziji, Siriji, na Portugalskem, Črni Gori, Madeiri, na Madžarskem in na Kanarskih otokih. Poleg z različnimi vrstami peloda se vrsta E. stipulatus največrat prehranjuje $\mathrm{s}$ fitofagno pršico Panonychus citri (McGregor) (Abad-Moyano in sod., 2010).

Dosedanje raziskave kažejo, da se ta plenilska pršica lahko prehranjuje tudi z navadno pršico (Tetranychus urticae Koch), vendar pri njenem zatiranju ni tako učinkovita kot nekatere druge plenilske pršice, na primer Neoseiulus californicus (McGregor) in Phytoseiulus persimilis Athias-Henriot. Pomembna neželena lastnost pršice $E$. stipulatus je, da pleni jajčeca ostalih vrst plenilskih pršic, s katerimi tekmuje za hrano (Abad-Moyano in sod., 2010). McMurtry in sod. (1992) navajajo, da so »splošni plenilci«, kamor spadajo predstavniku rodu Euseius, pri zmanjševanju populacij fitofagnih pršic učinkoviti predvsem takrat, kadar je njihova populacija nizka.

\subsubsection{Euseius finlandicus (Oudemans, 1915)}

Ta pršica se najpogosteje pojavlja na listih sadnega drevja, kot so jablane, breskve in češnje (Broufas in Koveos, 2001). Najdemo pa jo tudi na listih drugih drevesnih vrst (Cercis sp., Crataegus sp., Ligustrum sp., Pittosporum sp., Juglans sp., Morus alba L., Rubus ulmifolius Schott idr.), tudi takšnih, ki rastejo v gozdu. Omenjena pršica je ena od redkih vrst iz rodu Euseius, ki se pojavljajo $\mathrm{v}$ območjih $\mathrm{z}$ zmernih podnebjem (Broufas in Koveos, 2001), pri nas pa smo jo prvič našli 21. junija 2013 na listih sliv na Zgornji Lipnici.

Ta plenilska vrsta velja za enega od pomembnejših naravnih sovražnikov fitofagnih pršic $\mathrm{v}$ sadovnjakih (Abdallah in sod., 2001). Glede na način prehranjevanja jo uvrščamo med splošne plenilce fitofagnih pršic in specialiste na pelodu (Schausberger in Croft, 1999, Kasap, 2009), saj se lahko prehranjuje (in svoj razvojni krog zaključi) na pršicah prelkah (Tetranychidae), pršicah šiškaricah (Eriophyidae), mehkokožnatih pršicah (Tarsonemidae) in pršicah iz družine AcaridaeTyroglyphidae. Prehranjuje pa se lahko tudi s pelodom različnih rastlinskih vrst (Kasap, 2009), celičnim sokom, sporami gliv, $\mathrm{z}$ medeno roso in $\mathrm{z}$ jajčeci in ličinkami manjših žuželk (Abdallah in sod., 2010). Razvojni krog te pršice je glede na ugotovitve Abdallah et al. (2010) najkrajši, ko pleni pršice šiškarice, najdaljši pa tedaj, ko se pršica prehranjuje s pelodom. Omenjena plenilska vrsta velja za pomembnega naravnega sovražnika fitofagnih pršic, kot sta vrsti Panonychus ulmi in Aculus schlectendali (Nalepa) (Kasap, 2009).

\subsubsection{Euseius gallicus (Kreiter \& Tixier, 2009)}

Vrsta je bila v Evropi prvič najdena na jugu Francije leta 2010 (Tixier et al., 2010), v Sloveniji pa 21. julija 2017 v Šempetru pri Gorici na listih robide. Dőker in sod. (2014) navajajo njeno zastopanost še v Belgiji, Turčiji, Nemčiji in na Nizozemskem. Za splošne plenilce iz rodu Euseius velja, da se lahko prehranjujejo tudi na pelodu. Pršica Euseius gallicus zelo hitro zaključi razvojni krog ob prisotnosti peloda širokolistnega rogoza (Typha latifolia L.) (Van Houten et al., 2016).

Dosedanje raziskave omenjeno to plenilsko vrsto kot učinkovitega naravnega sovražnika rastlinjakovega ščitkarja na vrtnicah (Van Houten in sod., 2016). Ko se samice vrste E. gallicus prehranjujejo $\mathrm{z}$ jajčeci rastlinjakovega ščitkarja, navadno odložijo več jajčec (3,6 jajčec na dan), kot pri hranjenju $\mathrm{z}$ ličinkami cvetličnega resarja ( 1,5 jajčeca/dan). Preferenca plenilca do različne hrane se kaže $\mathrm{v}$ situacijah, ko ima na razpolago več vrst hrane, saj ob razpoložljivosti peloda širokolistnega rogoza in ličink cvetličnega resarja raje izbere pelod (Van Houten in sod., 2016). Krajšanje dneva ne vpliva na vstop samic $\mathrm{v}$ diapavzo. Znano je tudi, da razvoj mlajših stadijev pršic poteka tudi pri $13{ }^{\circ} \mathrm{C}$ (Van Houten in sod., 2016).

Podjetje Biobest Belgium N.V. skrbi, da je omenjena pršica tržno dostopna $\mathrm{v}$ pripravku Dyna-Mite ${ }^{\circledR} \mathrm{G}$ System. Glede na navedbe v tehničnem listu pripravka (Technical sheet..., 2018) lahko plenilska pršica svoj razvojni krog razvije že pri $10{ }^{\circ} \mathrm{C}$, pa vse do $32{ }^{\circ} \mathrm{C}$. Njen razvoj je možen že pri $50 \%$ relativni zračni vlagi. Idealne razmere za razvoj plenilca so sicer pri $25{ }^{\circ} \mathrm{C}$ in $70-80 \%$ relativni zračni vlagi.

\subsection{Kampimodromus abberans (Oudemans, 1930)}

To pršico uvrščamo v poddružino Amblyseiinae Muma, kamor poleg plemena Kampimodromini Kolodochka uvrščamo še 8 plemen. Doslej so $\mathrm{v}$ pleme Kampimodromini uvrstili 90 vrst plenilskih pršic iz različnih rodov (Chant in McMurtry, 2006).

V rodu Kampimodromus Nesbitt, 1951 je trenutno 15 vrst. Vrsto $K$. abberans smo našli na dveh različnih lokacijah v Slovenski Istri, in sicer 7. septembra 2016 v Vinjolah in na posestvu Purissima na listih fig, 21. julija 2017 pa na navedenem posestvu na listih kumar v rastlinjaku, v Šempetru pri Gorici na listih malin na prostem in v Novi Gorici na listih vrtnic na prostem. Prva najdba te vrste pri nas sicer datira v leto 2006, ko je bila najdena na listih jablane (Miklavc, 2006; Bohinc and Trdan, 2013).

Pršico $K$. abberans so med drugim našli na jablani, leski in vinski trti. Pojavlja se v Evropi in v Severni Ameriki. Velja za pomembnega naravnega sovražnika pršice prelke Eotetranychus carpini (Oudemans) in pršic šiškaric. Ob odsotnosti pršic se lahko prehranjuje na ličinkah ameriškega kaparja (Diaspidiotus perniciosus [Comstock]) in pelodu različnih rastlinskih vrst 
(Broufas in sod., 2007). Duso in sod. (2009) navajajo, da je ta plenilec zelo občutljiv na fitofarmacevtska sredstva, zato je $\mathrm{v}$ intenzivni pridelavi jabolk praktično ne zasledimo. Zaradi njene učinkovitosti pa je veliko raziskav usmerjenih $\mathrm{v}$ iskanje odpornih populacij na fitofarmacevtska sredstva.

\subsection{Neoseiulus californicus (McGregor, 1954)}

Prve najdbe tega plenilca $\mathrm{v}$ Sloveniji datirajo $\mathrm{v}$ leto 2012 (Trdan in sod., 2013), ko je bil 29. avgusta $\mathrm{v}$ Kortah najden na jajčevcu na prostem, 30 . avgusta pa $\mathrm{v}$ Ljubljani na melonah $\mathrm{v}$ rastlinjaku in na jablani. 21. julija 2017 je bila pršica najdena tudi v Bukovici pri Novi Gorici, in sicer na papriki v rastlinjaku.

Vrsta $N$. californicus spada med plenilske pršice, katere so že izvorno zastopane na območju Sredozemlja in na območjih z njemu podobnim podnebjem po celem svetu. Glede na način prehranjevanja jo uvrščamo v skupino pršic tipa II-III, kar pomeni, da za svoj plen izbira specifične skupine fitofagnih organizmov. Omenjena plenilska vrsta se omenja kot uspešen biotični agens pri zatiranju pršic prelk (Tetranychidae), predvsem navadne pršice (Tetranychus urticae) (Kim sod., 2012) in rdeče sadne pršice (Panonychus ulmi) (El Taj in Jung, 2012). Prehranjuje se lahko tudi s pelodom in drugimi malimi žuželkami (Ferragut Peréz in sod., 2010) ter z mehkokožnimi pršicami.

Omenjena pršica dobro prenaša tudi nizko zračno vlago (Weintraub in Palevsky, 2008) in visoke temperature (Ferragut Peréz in sod., 2010). Pri zanjo idealnih razmerah $\left(15-35^{\circ} \mathrm{C}\right)$ in dostopnostjo vrste Tetranychus urticae (kot plena) ima lahko omenjena plenilska pršica do 28 rodov na leto (Weintraub in Palevsky, 2008).

Najdba vrste $N$. californicus, ki je znana tudi pod starim imenom Amblyseius californicus, je bila prvič omenjena v Kaliforniji (Zhang, 2003). Danes jo najdemo tudi v Srednji in Južni Ameriki in v Južni Evropi (Zhang, 2003; Walzer in sod., 2007), kar kaže, da ji bolj ugajajo aridna območja. Pojavlja se na sadnih vrstah (marelice, breskve, jablane, hruške, kivi, citrusi, vinska trta), poljščinah (soja, koruza, bombaž,...) in na zelenjadnicah (jajčevec, bučke, paprika, solata,...) (Ferragut Peréz in sod., 2010). Nekatere rase so zelo odporne na fitofarmacevtska sredstva, kar omogoča lažjo uporabo tega biotičnega agensa $\mathrm{v}$ integriranem varstvu rastlin (Walzer in sod., 2007).

Vrsta $N$. californicus velja med pršicami iz družine Phytoseiidae za tržno najbolj dostopno (Walzer in sod.,
2007). Glede na podatke EPPO je uporaba omenjene vrste kot komercialnega biotičnega pripravka že dovoljena v Belgiji, Nemčiji, Franciji, Grčiji, Italiji, Španiji, Švici, Tuniziji in na Češkem, Danskem, Finskem, Nizozemskem (List of biological control agents ..., 2018).

\subsection{Paraseiulus triporus (Chant \& Shaul, 1982), Phytoseius horridus (Ribaga, 1904) in Amblyseius andersoni (Chant, 1957)}

Plenilska pršica Paraseiulus triporus je bila v Sloveniji prvič najdena leta 2006 na jablanah (Miklavc, 2006, Bohinc and Trdan, 2013). V letu 2017 smo jo 21. julija našli $\mathrm{v}$ Bukovici na kumarah $\mathrm{v}$ rastlinjaku. Rod Paraseiulus uvrščamo v prvo skupino plenilskih pršic, kamor spadajo vrste, ki se prehranjujejo samo na prelkah (McMurtry in sod., 2013).

Dosedanje raziskave omenjajo njeno zastopanost $\mathrm{v}$ Srbiji (Mladenović in sod., 2013), Franciji (van der Linden, 2008), Grčiji (Papadoulis and Emmanouel, 1997), na Češkem (Kabicek, 2010; Kabicek 2017), Slovaškem (Praslicka in sod., 2009) in Madžarskem (Szabo in sod., 2013).

Pršico Phytoseius horridus smo našli v dveh različnih travniških sadovnjakih, in sicer v Rakitnici in Kočevski Reki, v juniju 2014, kar je omenjeno že v Bohinc and Trdan (2015). Gre za prvo najdbo te vrste v Sloveniji, ki sicer nima večjega gospodarskega pomena.

Plenilska pršica Amblyseius andersoni je bila $\mathrm{v}$ Sloveniji prvič ugotovljena že v letu 2006 (Miklavc, 2006; Bohinc and Trdan, 2013). V letu 2017 smo jo našli na listih fige 21. avgusta $\mathrm{v}$ Slovenski Istri (Sermin, Bertoki). Omenjena pršica je $\mathrm{v}$ naravi zastopana na območju Palearktika in Nearktika. Je pomemben naravni sovražnik pršic Aculops lycopersici (Tryon), Aculus schlechtendali, Panonychus ulmi, Phytonemus pallidus (Banks), Polyphagotarsonemus latus (Banks), Tetranychus urticae in Tetranychus cinnabarinus (Boisduval). V varstvu rastlin $\mathrm{v}$ tržni pridelavi se ta plenilska pršica uporablja v Franciji, Italiji, Španiji, Sloveniji in na Poljskem (List of biological control agents ..., 2018).

Pršica Amblyseius andersoni spada v skupino III, kamor uvrščamo plenilske pršice, ki so splošni plenilci. Kot koristni organizem je najbolj učinkovita na listih trte, ki niso poraščeni s trihomi (McMurtry et al., 2013). 


\section{SKLEPI}

Naša raziskava je temeljila na preučevanju zastopanosti plenilskih pršic na različnih gojenih rastlinah. Ugotovili smo, da je na Seznam tržno dostopnih koristnih organizmov v Evropi uvrščenih 16 vrst plenilskih pršic (List of biological control agents ..., 2018). Na podlagi rezultatov naše raziskave sta bili na Seznam domorodnih vrst organizmov za namen biotičnega varstva rastlin v Sloveniji uvrščeni plenilski pršici Amblyseius andersoni in Neoseiulus californicus.

Poleg omenjenih dveh pa bo v bližnji prihodnosti na ta seznam uvrščena tudi pršica Euseius gallicus, za katero sicer skromno število raziskav potrjuje, da je lahko učinkovit plenilec ličink rastlinjakovega ščitkarja (Trialeurodes vaporariorum). Ta pršica je uporabna predvsem v okrasnem vrtnarstvu, saj je zelo učinkovita pri varstvu vrtnic pred rastlinjakovim ščitkarjem. Kljub temu, da ima rastlinjakov ščitkar tudi druge naravne sovražnike, pa je njihov razvoj otežen, saj odlagajo jajčeca na liste in cvetove vrtnic, ki so podvrženi hitrejšemu odstranjevanju (Van Heuten in sod., 2016).
Pri uporabi plenilskih pršic $\mathrm{v}$ integriranem varstvu rastlin je pomembnih več dejavnikov. Med drugim je potrebno paziti moramo na sočasno uporabo $s$ fitofarmacevtskimi sredstvi. Medtem, ko je le nekaj fungicidov škodljivih za plenilske pršice, velja omenjeno za skoraj vse insekticide in akaricide. $\mathrm{O}$ delovanju herbicidov na plenilske pršice je bilo do sedaj zelo malo raziskav (Fountain and Medd, 2015). Pomemben vpliv pri razmnoževanju plenilskih pršic imajo tudi dostopnost hrane, oblika lista in pelod gostiteljske rastline, kot tudi semiokemikalije, ki jih rastline oddajajo (Gerson, 2014).

Po doslej znanih podatkih zastopanosti plenilskih pršic v Sloveniji lahko ugotovimo, da je zastopanost plenilskih pršic v Sloveniji velika, a vse vrste niso ustrezne za implementacijo $\mathrm{v}$ okoljsko sprejemljive načine rastlinske pridelave. Zato bo potrebno nadaljevati $\mathrm{z}$ njihovim načrtnim spremljanjem, da bi našli morebitne nove vrste, ki se $\mathrm{v}$ drugih evropskih državah že uporabljajo v biotičnem varstvu rastlin.

\section{ZAHVALA}

Rezultati, predstavljeni $\mathrm{v}$ tem prispevku, so bili pridobljeni $\mathrm{v}$ okviru Programa strokovnih nalog $\mathrm{s}$ področja zdravstvenega varstva rastlin, ki ga financira
Ministrstvo za kmetijsko, gozdarstvo in prehrano RS Uprava RS za varno hrano, veterinarstvo in varstvo rastlin.

\section{LITERATURA}

Abad-Moyano, R., Urbaneja, A., hoffmann, D., Schausberger, P. (2010). Effecrs of Euseius stipulatus on establishment and efficacy in spider mite suppression of Neoseiulus californicus and Phytoseiulus persimilis in clementine. Experimental and Applied Acarology, 50, 329-341. doi:10.1007/s10493-009-9320-9

Blackwood, J.S., Scausberger, P., Croft, B.A. (2001). Prey-stage preference in generalist and specialist phytoseiid mites (Acari: Phytoseiidae) when offered Tetranychus urticae (Acari: Tetranychidae) eggs and larvae. Environmental Entomology, 30(6), 1103-1111. doi:10.1603/0046-225X-30.6.1103

Bohinc, T., Trdan, S. (2013). Phytophagous and predatory mites in Slovenia. Acarologia, 53: 145150. doi:10.1051/acarologia/20132084

Bohinc, T., Trdan, S. (2015). Nove najdbe naravnih sovražnikov v Sloveniji v obdobju 2013-2014. V: Zbornik predavanj in referatov 12. Slovenskega posvetovanja o varstvu rastlin $z$ mednarodno udeležbo. Trdan, S. (ur.), 3.-4. marec 2015, Ptuj. Društvo za varstvo rastlin Slovenije, Ljubljana: 289-294.

Bouras, S.L., Papadoulis, G.T. (2005). Influence of selected fruit tree pollen on life history of Euseius stipulatus (Acari: Phytoseiidae). Experimental and Applied Acarology, 36:1-4. doi:10.1007/s10493005-2381-5

Broufas, G.D., Pappas, M.I., Koveos, D.S. (2007). Development, survival and reproduction of the predatory mite Kampimodromus abberans (Acari: Phytoseiidae) at different contant temperatures. Environmental Entomology, 36, 657-665. doi:10.1093/ee/36.4.657

Chant, D.A., McMurtry, J.A. (2006). A review of the subfamily Amblyseiinae Muma (Acari: Phytoseiidae): part IX. an overview. International Journal of Acarology, 32:2, 125-152, doi:10.1080/01647950608684453 
Dőker, I., Witters, J., Pijnakker, J., Kazak, C., Tixier, Marie-Stéphane, Kreiter, S. (2014). Euseius gallicus Kreiter and Tixier (Acari: Phytoseiidae) is present in four more countries in Europe: Belgium, Germany, The Netherlands and Turkey. Acarologia, $\quad 54, \quad 245-248$. doi:10.1051/acarologia/20142132

Duso, C., Fanti, M., Pozzebon, A., Angeli, G. (2009). Is the predatory mite Kampimodromus aberrans a candidate for the control of phytophagous mites in European apple orchards? BioControl, 54, 369-382. doi:10.1007/s10526-008-9177-6

El Taj, H.F., Jung , C. (2012). Effect of temperature on the life-history traits of Neoseiulus califronicus (Acari: Phytoseiidae) fed on Panonychus ulmiExperimental and Applied Acarology, 56(3), 247-260.

Ferragut Pérez, F., Pérez Moreno, I., Irada Calvo, V.M., Escudero Comomar, L.A. (2010). Ácaros Depredadores en las plantas cultivadas. Familia Phytoseiidae. Ediciones Agrotécnicas, 202 str. [in Spanish]

Gerson, U. (2014). Pest control by mites (Acari): present and future. Acarologia, 54, 371-394. doi:10.1051/acarologia/20142144

Global Biodiversity Information Facility. (2018). https://www.gbif.org/ (23.3.2018)

Fountain, M.T., Medd, N. (2015). Integrating pesticides and predatory mites in soft fruit crops. Phytoparasitica, 43, 657-667. doi:10.1007/s12600015-0485-y

Kabicek, J. (2010). Scarceness of phytoseiid species cooccurrence (Acari: Phytoseiidae) on leaflets of Juglans regia. Plant Protection Science, 46, 79-82. doi:10.17221/32/2009-PPS

Kabicek, J. (2017). Maple trees - host plants for some phytoseiid mites. Scientia Agriculturae Bohemica, 48, 1-7. doi:10.1515/sab-2017-0001

Kasap, I. (2009). Influence of temperature on life table parameters of the predaceous mite Euseius finlandicus (Oudemans) (Acari: Phytoseiidae). Turkish Journal of Agriculture and Forestry, 33,2936

Kim, T., Ahn, J.J., Lee, J.H. (2012). Age- and temperature-dependent oviposition model of Tetranychus californicus (McGregor) (Acari: Phytoseiidae) with Tetranychus urticae as prey. Journal of Applied Entomology, Doi: 10.1111/j. 1439-0418.2012.01734.x

Kreiter, S., Payet, R.-M., Fillâtre, J., Azali, H.A. (2018a). First records of Phytoseiidae (Acari:
Mesostigmata) from one island of the Comoros Archipelago. Acarologia, 58(3), 529-545.

Kreiter, S., Zriki, G., Ryckewaert, P., Pancarte, C., Douin, M., Tixier, M.-S. (2018b). Phytoseiid mites of Martinique, with redescription of four species and new records (Acari: Mesostigmata). Acarologia, 58 (2), 366-407.

List of biological control agents widely used in the EPPO region. Appendix I. EPPO Standards on Safe use of Biological Control - PM 6/3. 2012. http://archives.eppo.int/EPPOStandards/biocontrol_ web/bio_list.htm\#biolist (13.1.2014)

Mladenović, K., Stojnić, B., Vidović, B., Radulović, Z. (2013). New records of the tribe Bryobiini Berlese (Acari: Tetranychidae:Bryobiinae) from Serbia, with notes about associated predators (Acari: Phytoseiidae). Archives of Biological Sciences, 65(3),1199-1210. doi:10.2298/ABS1303199M

McMurtry, J.A., Morse, J.G., Johnson, H.G. (1992). Studies of the impact of Euseius species (Acari: Phytoseiidae) on citrus mites using predator exclusion and predator release experiments. Experimental and Applied Acarology, 15, 233-248. doi:10.1007/BF01246565

McMurtry, J., De Moraes, G., Sourassou, N.F. (2013). Revision of the lifestyles of phytoseiid mites (Acari: Phytoseiidae) and implications for biological control strategies. Systematic \& Applied Acarology, 18: 297-320. doi:10.11158/saa.18.4.1

Palevsky, E., Reuveny, H., Okonis, O., Gerson, U. (1999). Comparative behavioural studies of larval and adult stages of the phytoseiids (Acari: Mesostigmata) Typhlodromus athiasae and Neoseiulus californicus. Experimental and Applied Acaralogy, 23, 467-485. doi:10.1023/A:1006187402722

Papadoulis, G.T., Emmanouel, N.G. (1997). New records of phytoseiid mites from Greece, with description of Typhlodromus krimbasi sp. nov. (Acarina, Phytodeiidae). Acarologia, 38, 21-28.

Praslicka, J., Bartekova, A., Scharmannova, J., Malina, R. (2009). Predatory mites of the Phytoseiidae familiy in integrated and ecological pest management systems in orchards in Slovakia. Biologia, 64, 959-961. doi:10.2478/s11756-0090163-y

Stojnić, B., Panou, H., Papadoulis, G., Petanović, R., Emmanouel, N. (2002). The present knowledge and new records of Phytoseiid and Tydeid mites (Acari: Pyhtoseiidae, Tydeidae) for the fauna of Serbia and Montenegro. Acta Entomologica Serbica, 7(1-2), 111-117. 
Szabo, A., Gal, C. Jr., Penzes, B. (2013). The occurrence of predatory mites in the Kunsag wine region, Hungary. Novenyvedelem, 49, 193-197.

Technical sheet Dyna-mite ${ }^{\circledR}$ G-System. 2018. Biobest Belgium N.V. https://www.biobestgroup.com/public/uploads/linke dfile/f537a1a4b437b78.53062353_TECHNICAL\% 20SHEET\%20DYNA-MITE\%20G-

SYSTEM\%20(EN-240414).pdf (9.4.2018)

The list of registrated plant protection products on 17.1.2014 (2014). Ministry of Agriculture and Environment. The Administration of the Republic of Slovenia for Food Safety, Veterinary and Plant Protection. Accessed 1701 2014, available at http://spletni2.furs.gov.si/FFS/REGSR/index.htm

The Regulations on Integrated Production of Vegetables. (2013). The Republic of Slovenia, Ministry of Agriculture and Environment. Accessed $17 \quad 01 \quad 2014, \quad$ available http://www.mko.gov.si/fileadmin/mko.gov.si/pageu ploads/podrocja/Kmetijstvo/Integrirana_pridelava/ TN_zelenjava_2013.pdf.

Tixier, M.S., Kreiter, S., Douin, M., Moraes, G.J. (2012). Rates of description of Phytoseiidae mite species (Acari: Mesostigmata): space, time and body size variation. Biodiversity Conservation, 21, 993-1013. doi:10.1007/s10531-012-0235-0

Tixier, M.S., Kreiter, S., Okassa, M., Cheval, B. (2010). A new species of the genus Euseius Wainstein (Acari: Phytoseiidae) from France. Journal of Natural History, 44,241-254. doi:10.1080/00222930903383529

Trdan, S., Kavallieratos, N., Stathakis, T., Kreiter, S., Stojanović, A., Tomanović, Ž., Bohinc, T. (2013). Prve najdbe treh vrst naravnih sovražnikov v Sloveniji: plenilske pršice Neoseiulus californicus (Arachnida, Acari, Phytoseiidae) in parazitoidnih os Neochrysocharis formosus (Insecta, Hymenoptera,
Eulophidae) in Dibrachys microgastri (Insecta, Hymenoptera: Pteromalidae). V: Zbornik predavanj in referatov 11. slovenskega posvetovanja o varstvu rastlin $z$ mednarodno udeležbo (in Okrogle mize o zmanjšanju tveganja zaradi rabe FFS v okviru projekta CropSustaIn). Bled, March 5-6 2013. Trdan, S., Maček, J. (ur.). Društvo za varstvo rastlin Slovenije: 286-294.

Van der Linden, (2008). Natural occurrence and establishment of predatory mites (Acari: Phytoseiidae) on nurseries for amenity trees. V: Working Group "Integrated Control in Protected Crops, Temperate Climate", Proceedings of the Working Group meeting, Sint Michielsgestel, Netherlands, 21-25 April 2008. Bulletin OILB/SROP , 32, 231-234.

Van Houten, Y., Hoogerbrugge, H., Lenferink, K.O. (2016). Evaluation of Euseius gallicus as a biological control agent of western flower thrips and greenhouse whitefly in rose. Journal of the Acarological Society of Japan, 25,147-159. doi:10.2300/acari.25.Suppl_147

Walzer, A., Castagnoli, M., Simoni, S., Ligouri, M., Palevsky, E., Scausberger, P. (2007). Intraspecific variation in humidity susceptibility of the predatory mite Neoseiulus californicus: survival, development and reproduction. Biological Control, 41, 42-52. doi:10.1016/j.biocontrol.2006.11.012

Weintraub, P., Palevsky, E. (2008). Evaluation of the predatory mite, Neoseiulus californicus, for spider mite control on greenhouse sweet pepper under hot arid field conditions. Experimental and Applied Acaralogy, 45, 29-37. doi:10.1007/s10493-0089169-3

Zhang Z.Q. (2003). Mites in greenhouse: identification, biology and control — Cambridge: CABI Publishing Press. pp. 235. 